\title{
PELATIHAN DETEKSI ADANYA FORMALIN, BORAKS, DAN PEWARNA BERBAHAYA DALAM MAKANAN SERTA PENYULUHAN BAHAYANYA BAGI KESEHATAN MASYARAKAT DESA MEURANDEH DAYAH KOTA LANGSA
}

\author{
Seprianto 1), Molani Paulina Hasibuan 1), Desy Irafadillah Effendi ${ }^{2)}$ \\ ${ }^{1)}$ Program Studi Pendidikan Kimia, Universitas Samudra \\ 2) Program Studi Pendidikan Bahasa Indonesia, Universitas Samudra \\ seprianto_kimia@unsam.ac.id
}

DOI : 10.31604/jpm.v2i1.21-25

\begin{abstract}
This Community Service Program aims to train people to make simple tools that can detect the presence of formalin and borax in food so that people are helped in choosing safe food ingredients. The target partners of the training activities were mothers in Meurandeh Dayah Village. Based on preliminary search, partners have not yet realized the dangers of food containing prohibited additives such as formalin, borax and harmful dyes to health. Partners also do not know the simple way to detect the presence of formalin, borax, and forbidden dyes such as Rhodamine B in food. Therefore, the activities carried out include socialization about the dangers of prohibited additives in food and training to make simple tools to detect the presence of formalin and borax using turmeric and toothpicks. The activity continued with the practice of detecting the presence of prohibited additives in food using simple tools that have been made. This activity contributes to improving the level of public health through the skills to choose food that is safe for health.
\end{abstract}

Keywords: Training, Borax, Formalin, Harmful Dyes, Additives.

\begin{abstract}
Abstrak
Program Pengabdian Kepada Masyarakat ini bertujuan untuk melatih masyarakat membuat alat sederhana yang dapat mendeteksi adanya formalin dan boraks dalam makanan sehingga masyarakat terbantu dalam memilih bahan pangan yang aman. Mitra sasaran kegiatan pelatihan adalah ibu-ibu di Desa Meurandeh Dayah. Berdasarkan penelusuran awal, mitra belum menyadari bahaya makanan yang mengandung zat aditif terlarang seperti formalin, boraks dan pewarna berbahaya terhadap kesehatan. Mitra juga belum tahu sederhana untuk mendeteksi adanya formalin, boraks, dan pewarna terlarang seperti Rhodamin B dalam makanan. Oleh karena itu, kegiatan yang dilaksanakan meliputi sosialisasi tentang bahaya zat aditif terlarang dalam makanan dan pelatihan membuat alat sederhana untuk mendeteksi adanya formalin dan boraks menggunakan kunyit dan tusuk gigi. Kegiatan dilanjutkan dengan praktek mendeteksi adanya zat aditif terlarang dalam makanan menggunakan peralatan yang telah dibuat. Kegiatan ini berkontribusi dalam peningkatan taraf kesehatan masyarakat melalui keterampilan memilih bahan pangan yang aman bagi kesehatan.
\end{abstract}

Kata kunci: Pelatihan, Boraks, Formalin, Pewarna Terlarang, Zat Aditif.

MARTABE : Jurnal Pengabdian Masyarakat|21 


\section{PENDAHULUAN}

Peran bahan tambahan pangan khususnya bahan pengawet menjadi semakin penting sejalan dengan kemajuan teknologi produksi bahan tambahan pangan sintetis. Bahan pengawet umumnya digunakan untuk mengawetkan pangan yang sifatnya mudah rusak. Berdasarkan Peraturan Menteri Kesehatan Republik Indonesia Nomor 33 Tahun 2012 tentang Bahan Tambahan Pangan (BTP), jenis bahan tambahan pangan golongan pengawet yang dilarang penggunaannya dalam produk pangan antara lain adalah formalin dan asam borat. Formalin biasanya digunakan sebagai bahan pengawet mayat dan pengawet hewan untuk penelitian. Formalin juga berfungsi sebagai desinfektan, antiseptik, antihidrolik serta bahan baku industri pembuatan lem plywood, resin dan tekstil (Saparinto dan Hidayati, 2010). Sedangkan asam borat atau yang ikenal dengan nama boraks dalam kesehariannya berfungsi sebagai pembersih, fungisida, herbisida dan insektisida yang bersifat toksik pada manusia (Eka, 2013).

pewarna tekstil. Harga menjadi salah satu alasan oleh produsen untuk menggunakan zat pewarna tekstil untuk ditambahkan pada produk makanan mereka, dimana zat pewarna tekstil relatif lebih murah dan biasanya warnanya lebih menarik dibanding dengan zat pewarna makanan. Rhodamin B dan methanil yellow bersifat karsinogenik sehingga dalam penggunaan jangka panjang dapat menyebabkan kanker dan tumor pada organ tubuh manusia Akhir-akhir ini dengan banyak ditemukan produkproduk pangan seperti tahu, bakso, mie serta jajanan anak sekolah yang mengandung bahan-bahan kimia berbahaya sehingga menyebabkan masyarakat perlu hati-hati dalam mengkonsumsi jenis-jenis makanan tersebut. Makanan tersebut sering dijual dilingkungan sekolah oleh penjaja makanan, serta terjual bebas di masyarakat. Banyaknya produk-produk pangan yang mengandung bahan berbahaya tercermin dari hasil pengawasan Badan Pengawasan Obat dan Makanan (BPOM).

Kecamatan Langsa Lama khususnya desa Meurandeh Dayah merupakan pusat pendidikan di kota Langsa. Banyak sekolah yang terdapat di kecamatan ini mulai dari tingkat PAUD sampai dengan perguruan tinggi. Bahkan kedua perguruan tinggi negeri di kota Langsa terdapat di desa Meurandeh Dayah. Akses yang mudah serta banyaknya peminat membuat para pedagang ramai-ramai mengunakan bahan tambahan pangan mulai dari yang alami hingga bahan kimia yang dilarang penggunaannya seperti formalin, boraks, dan pewarna tekstil. Hal ini bertujuan untuk mencegah makanan menjadi rusak dan cepat basi serta warnanya lebih menarik. Kualitas bahan pangan dan jajanan yang kurang baik ini memperburuk dan menganggu asupan gizi sehingga menimbulkan beberapa penyakit.

Berdasarkan hasil wawancara dengan pihak mitra, permasalahan prioritas yang dihadapi mitra adalah: bahaya dan penyakit yang dapat ditimbulkan jika mengkonsumsi makanan yang mengandung formalin, boraks dan pewarna terlarang belum dikenali; alat sederhana untuk mendeteksi adanya formalin, boraks dan pewarna terlarang belum ada; dan keterampilan mendeteksi adanya formalin, boraks, dan pewarna terlarang dalam makanan secara sederhana belum ada. 


\section{METODE PELAKSANAAN}

Berdasarkan permasalahan prioritas yang dihadapi mitra dan hasil kesepakatn antara tim pengusul dengan mitra maka ditawarkan solusi sebagai berikut: penyuluhan bahaya formalin, boraks, dan pewarna terlarang bagi kesehatan; pelatihan membuat alat sederhana pendeteksi adanya formalin, boraks dan pewarna terlarang; pelatihan teknik mendeteksi adanya formalin, boraks dan pewarna berbahaya dalam makanan. Tujuan kegiatan PKM ini yaitu mencegah bahaya dan penyakit yang ditimbulkan adanya bahan kimia terlarang dalam makanan serta menghasilkan alat sederhana pendeteksi adanya formalin, boraks dan pewarna terlarang dalam bahan makanan.

Output kegiatan PKM terdiri atas peralatan sederhana pendeteksi adanya bahan kimia terlarang dalam makanan serta keterampilan mendeteksi adanya bahan kimia terlarang dalam makanan. Sementara outcome yang diharapakan adalah peningkatan taraf kesehatan masyarakat, peningkatan kesadaran masyarakat dalam memilih bahan pangan yang aman, dan ketersediaan alat sederhana pendeteksi adanya bahan kimia terlarang. Sumber daya mitra yang mendukung kegiatan ini terdiri atas ketersediaan bahan-bahan sederhana dan perlatan yang dibutuhkan serta ketersediaan tempat pertemuan untuk melakukan pelatihan dan penyuluhan.

Prosedur kerja untuk mendukung realisasi metode yang ditawarkan kepada mitra dapat dilihat pada Gambar 1.

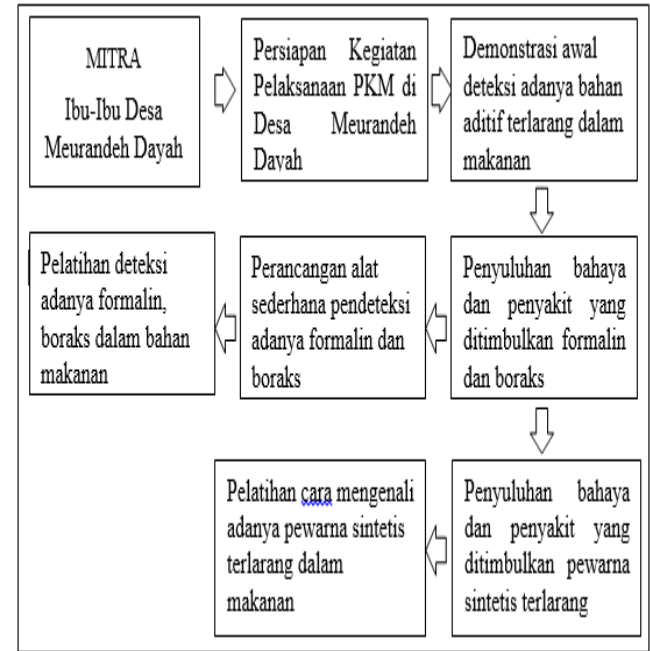

Gambar 1: Bagan Prosedur Kerja Realisasi Metode yang Ditawarkan

terdiri $\begin{gathered}\text { Rencana } \\ \text { atas }\end{gathered} \begin{gathered}\text { kegiatan } \\ \text { tahap }\end{gathered}$ pKM ini pelaksanaan, monitoring, dan evaluasi. Pada tahap persiapan, tim pelaksana berperan dalam pengadaan alat dan bahan kegiatan dan sosialisasi kegiatan PKM yang akan dilaksanakan. Sementara itu peran mitra dalam tahap persiapan yaitu menyiapkan tempat pertemuan dan menerima pengarahan dan sosialisasi rencana pelaksanaan kegiatan PKM.

Pada tahap pelaksanaan, tim pelaksana melakukan kegiatan: mengenalkan bahaya zat aditif terlarang dalam makanan; melatih membuat alat sederhana pendeteksi formalin, boraks dan pewarna sintetis terlarng; dan melatih cara mendeteksi adanya bahan aditif terlarang dalam makanan. Sementara itu, peran mitra dalam tahap pelaksanaan kegiatan yaitu menyiapkan bahan makanan yang ingin diuji. Pada tahap monitoring dan evaluasi terdiri dari pengujian pemahaman mitra mengenai kegiatan yang telah dilaksanakan yang terdiri atas tes yang berisi tentang pertanyaan-pertanyaan terkait materi tentang formalin, boraks, 
dan pewarna berbahaya dalam makanan.

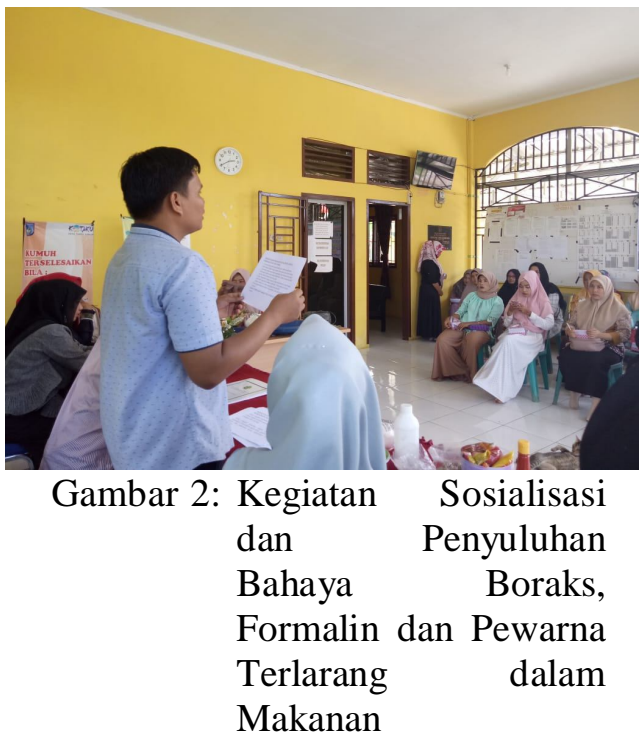

\section{HASIL DAN PEMBAHASAN}

Pendeteksian terhadap adanya kandungan formalin dan boraks adalah dengan cara menyediakan alat deteksi sederhana yang terbuat dari tusuk gigi dan kunyit. Kunyit baiknya di-blender atau digiling terlebih dahulu agar dapat direndam dengan tusuk gigi agar deteksi yang dilakukan dapat maksimal.

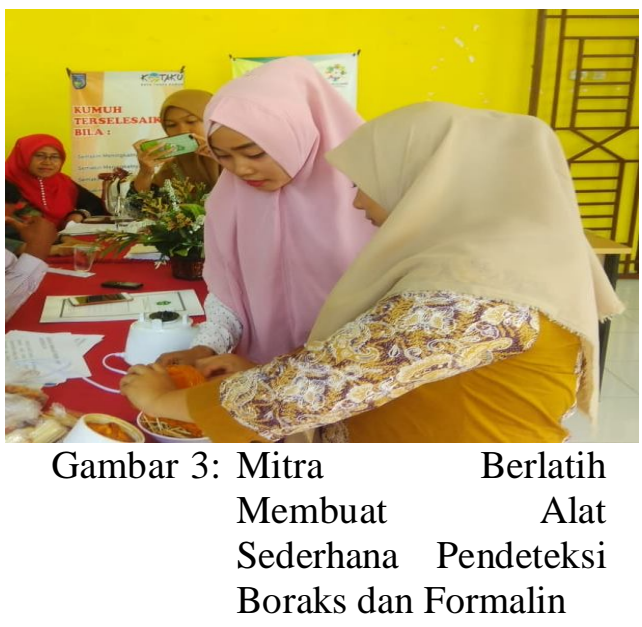

Gambar tusuk gigi yang telah dicampur dengan rendaman kunyit yang telah digiling dapat dilihat pada gambar di bawah ini.

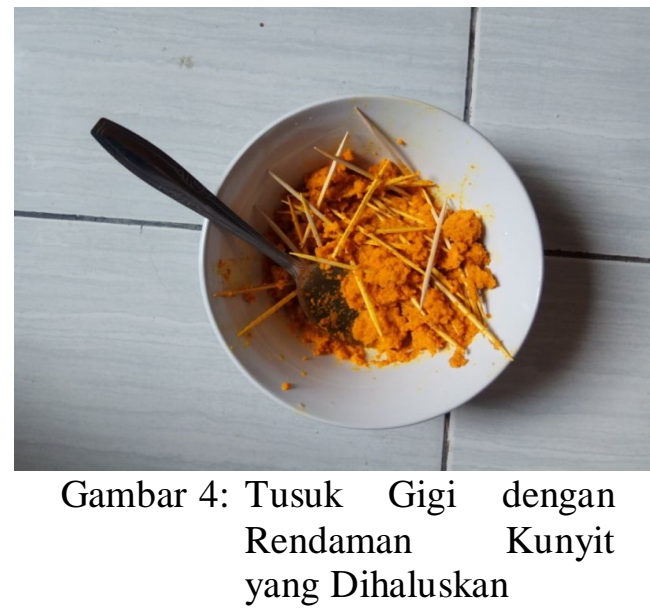

Tusuk gigi yang telah direndam dengan kunyit akan berwarna kuning seperti yang ditunjukkan pada gambar di bawah ini.

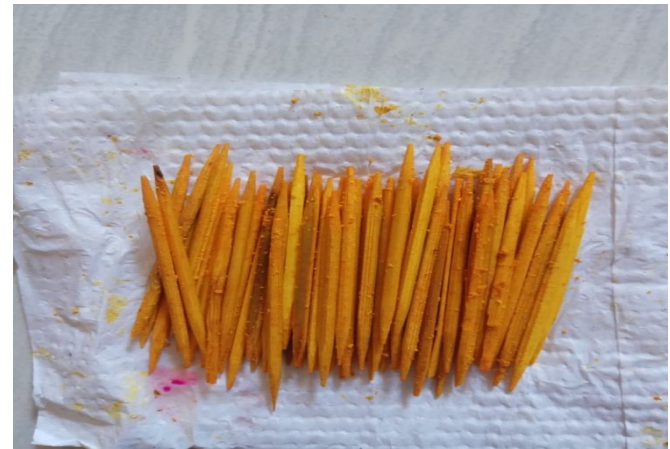

Gambar 5: Tusuk Gigi Pendeteksi Adanya Formalin dan Boraks

Sampel produk seperti mie aceh, ikan, bakso, dan saos yang diambil dari pasar lokal sebelum dan sesudah dilakukan pengujian terhadap kandungan formalin, boraks, dan Rhodamin B oleh masyarakat mitra dapat dilihat dari gambar berikut. 


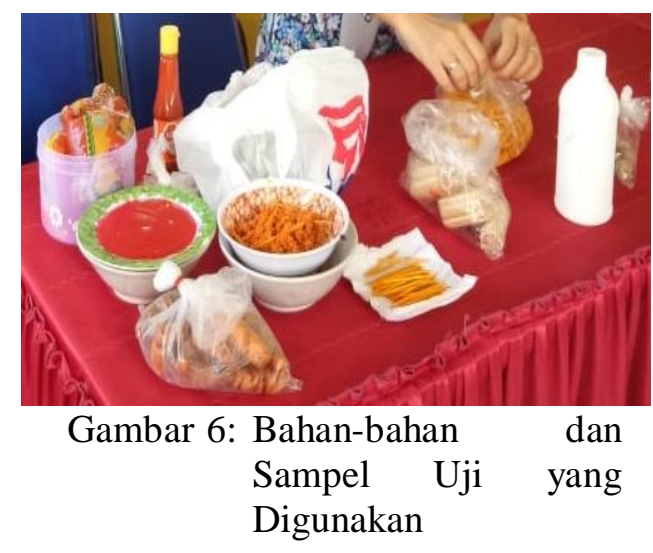

Sampel bahan makanan seperti mie aceh, saos, bakso, dan ikan yang biasanya mengandung bahan aditif berbahaya akan diuji kandungannya. Jika bahan makanan positif mengandung formalin dan boraks maka tusuk gigi yang telah dibaluri dengan kunyit akan berubah warna menjadi orange atau merah bata, sedangkan hasil negatif ditunjukkan oleh tusuk gigi yang masih berwarna kuning.

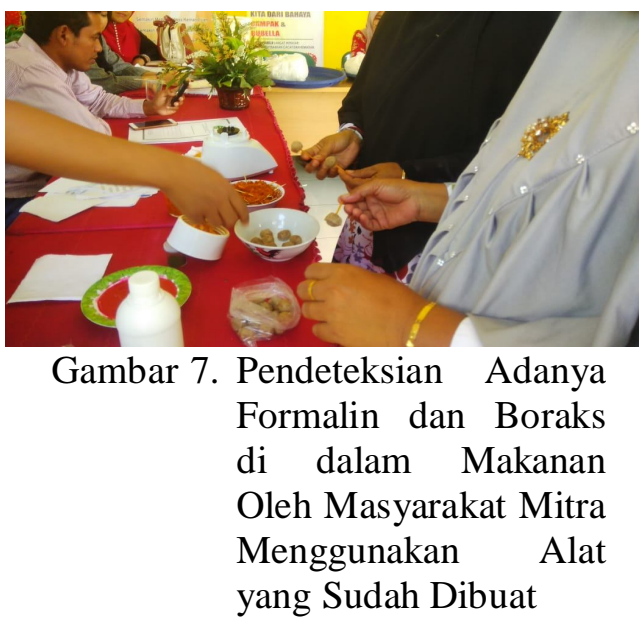

Sementara itu jika bahan makanan mengandung Rhodamin B, maka warna makanan tersebut tidak menghilang dengan segera jika makanan tersebut dioleskan ke kulit. Makanan yang tidak mengandung Rhodamin B warnanya akan menghilang dengan segera jika dioleskan ke kulit.

\section{KESIMPULAN}

Berdasarkan kegiatan yang telah dilakukan dapat disimpulkan bahwa pemahaman awal masyarakat mengenai zat aditif terlarang dalam bahan makanan seperti formalin, boraks, dan pewarna berbahaya masih terbatas. Namun, masyarakat sangat antusias dalam mengenal secara langsung jenisjenis dan cara mendeteksi adanya zat aditif terlarang dalam bahan makanan serta dampaknya terhadap kesehatan tubuh manusia. Masyarakat termotivasi untuk berpartisipasi aktif membuat sendiri alat sederhana pendeteksi adanya formalin dan boraks dengan memanfaatkan bahan-bahan yang mudah diperoleh di sekitar mereka yaitu kunyit dan tusuk gigi. Masyarakat mencoba sendiri mengenali makanan yang mengandung boraks dan formalin menggunakan alat yang telah dibuat sendiri.

\section{DAFTAR PUSTAKA}

BPS Kota Langsa. 2017. Kecamatan Langsa Lama dalam Angka 2017. Katalog BPS: 1102001.1173011.

Cahyadi, W. (2009). Analisis dan Aspek Kesehatan Bahan Tambahan Pangan, Edisi Kedua. Jakarta: Bumi Aksara.

Eka, R. (2013). Rahasia Mengetahui Makanam Berbahaya. Jakarta: Titik Media Publisher.

Saparinto, C. dan Hidayati, D. (2010). Bahan Tambahan Pangan. Yogyakarta: Kanis

Harahap, F.S. Atifah, Y. Dan Batubara, M.S. (2017). Penyuluhan jajanan sehat, deteksi kandungan formalin dan boraks. MARTABE: Jurnal Pengabdian Mayarakat Vol. 1 No. 1, hal 12-16. 